\begin{tabular}{|c|c|c|c|c|c|c|}
\hline \multirow{4}{*}{ Impact Factor: } & ISRA (India) & $=3.117$ & SIS (USA) & $=0.912$ & ICV (Poland) & $=6.630$ \\
\hline & ISI (Dubai, UAE & $=0.829$ & РИНЦ (Russia & $=0.156$ & PIF (India) & $=1.940$ \\
\hline & GIF (Australia) & $=0.564$ & ESJI (KZ) & $=8.716$ & IBI (India) & $=4.260$ \\
\hline & JIF & $=1.500$ & SJIF (Morocce & $=5.667$ & OAJI (USA) & $=0.350$ \\
\hline
\end{tabular}

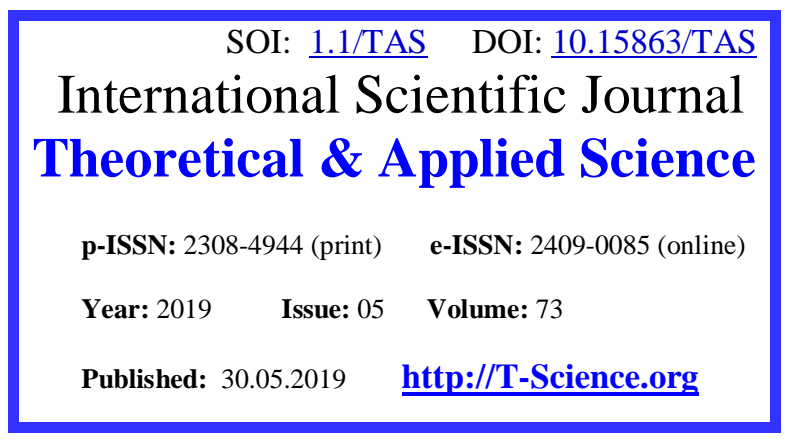

QR - Issue
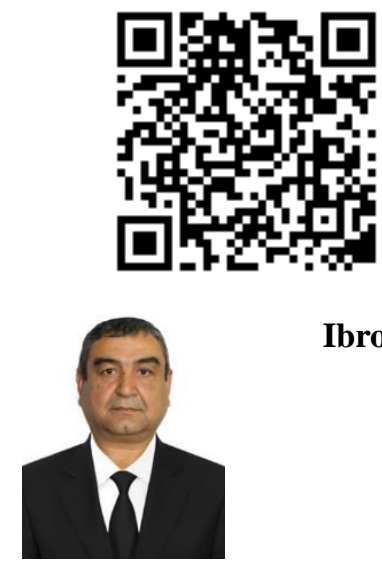

QR - Article

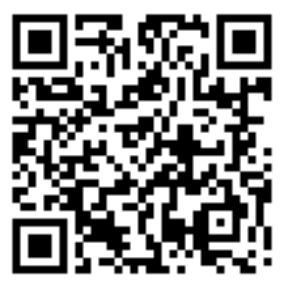

Ibrohim Urmanovich Darvishov senior teacher, $(\mathrm{PhD})$

Namangan State University, +998975938088 ibmofifar@bk.ru

\title{
SIGNS OF THE CONSONANT POSITIONS IN TURKIC LANGUAGES (The example sin Namangan area Kipchak dialects in republic of Uzbekistan)
}

Abstract: The article is about the consonants in the Namangan area Kipchak dialects, their strong and weak positions, comparing them with Turkic protolanguage and other Turkic languages in the world.

Key words: phonological opposition, correlation, phoneme tents, distribution, invariant, variant strong and weak position.

Language: Russian

Citation: Darvishov, I. U. (2019). Signs of the consonant positions in Turkic languages (The example sin Namangan area Kipchak dialects in republic of Uzbekistan). ISJ Theoretical \& Applied Science, 05 (73), $488-492$.

Soi: http://s-o-i.org/1.1/TAS-05-73-75 Doi: crossef https://dx.doi.org/10.15863/TAS.2019.05.73.75

\section{ПОЗИЦИОННЫЕ ЗНАКИ СОГЛАСНЫХ В ТЮРКСКИХ ЯЗЫКАХ (на примере кипчакских диалектов Намангана Республики Узбекистан)}

Аннотация: В статье рассматривается вопрос о сильных и слабых позициях согласных кыпчакского диалектного ареала Наманганской области путем сравнения с современными тюркскими языками, а также тюркским праязыком.

Ключевые слова: Фонологическая оппозиция, корреляциия, оттенки фонем, дистрибуциия, инвариант и вариант, сильная и слабая позиция.

\section{Introduction}

Известно, что фонема является единицей фонологии. Она признана лингвистической единицей во всех фонологических концепциях. Опорной точкой теории фонологии является фонологическое учение основателя Ленинградской фонологической школы И.А. Бодуэн де Куртене. Фонологические концепции как научный предмет сформировалась в Пражском лингвистическом кружке и отражена в труде Н.С. Трубецкого [9.216; 14.001-352].

Н.С. Трубецкой указал на необходимость подхода к фонеме, как к абстрактной единице определил конкретные звуки, как материальные символ фонема, которая может быть реализована несколькими звуками, являющимися вариантами фонем. Ученый утверждает, что любая фонема в системе фонологической оппозиции обладает определенной структурой, благодаря чему приобретает определенное фонологическое значение [14.001-352].
В связи с логической обоснованностью противопоставлений, согласно трактовке А.А. Реформатского, слова и морфемы образуют значимые единицы языка и для разграничения фонемы должны быть противопоставлены друг другу. Такое противопоставление называется фонологической оппозицией [11. 211; 12.74-95].

\section{Materials and Methods}

B лингвистической литературе фонологическая оппозиция определяется следующим образом: фонологическая оппозиция - это сопоставление двух фонем на основе одного признака или противопоставление фонем на основе фонологических признаков [5.39].

Фонологические оппозиции классифицированы Н.С. Трубецким следующим образом:

1. По отношению к системе оппозиции: одномерная, пропорциональная, многомерная и обособленная оппозиция. 


\begin{tabular}{|c|c|c|c|c|c|c|}
\hline \multirow{4}{*}{ Impact Factor: } & ISRA (India) & $=3.117$ & SIS (USA) & $=0.912$ & ICV (Poland) & $=6.630$ \\
\hline & ISI (Dubai, UAI & $=0.829$ & РИНЦ (Russia & $=0.156$ & PIF (India) & $=1.940$ \\
\hline & GIF (Australia) & $=0.564$ & ESJI (KZ) & $=8.716$ & IBI (India) & $=4.260$ \\
\hline & JIF & $=1.500$ & SJIF (Morocco & $=5.667$ & OAJI (USA) & $=0.350$ \\
\hline
\end{tabular}

2. В зависимости от отношение между членами оппозиции: оппозиция, различающаяся от другой наличием /отсутствием признака в одном из членов (привативная); основанная на степень раскрытия речевого аппарата.

3. По действию в разных позициях постоянная и нейтрализованная. [14.72-83].

Профессор А. Абдуазизов отмечает, что большое количество согласных фонем предполагает оппозицию между собой и такие парадигматические отношения требуют удобной их классификации. В связи с этим он рекомендует опираться на первичную классификацию фонологических оппозиций, предложенной проф. В.А. Васильевым, так как он создает благоприятные условия для применения классификации оппозиции Н.С. Трубецкого. Кроме этого, с учетом вышеуказанного им представлена классификация оппозиции согласных звуков узбекского литературного языка. По мнению А. Абдуазизова, согласно классификации В.А. Васильева, каждая фонологическая оппозиция должна определяться между двумя фонемами $(\boldsymbol{n}-\boldsymbol{m}, \boldsymbol{m}-\boldsymbol{\kappa})$, и если имеется одна отличительная черта, от следует рассматривать как «одиночную оппозицию», если таких признаков два - «двойную оппозицию», если более двух - «множество оппозиций». Парадигматические отношения между согласными фонемами проявляются в бинарных оппозициях, состоящих из двух членов. [1.120].

Представитель

Ленинградской фонологической школы Л.В. Щерба также отмечал, что смыслоразличительная функция фонемы является ее главной отличительной чертой. Главное внимание он уделяет функциональной стороне фонемы, отодвигая на второй план еe артикуляционно-акустические свойства. Ученый отмечал также способность фонем образовать систему оппозиций. [15.185186]. Важным в фонологической теории Л.В. Щербы является учение об оттенках фонемы. Оттенки являются реальным видом произношения фонемы, все реально произносимые звуки являются оттенками (вариантами).

$$
\text { Варианты фонем (оттенки) }
$$

классифицируются разными учеными по-разному. Согласно теории пражской лингвистической школы и мнению Л.В. Щербы в речевом окружении один оттенок не выступать на месте другого. А в американском языкознании это явление называется дополнительной дистрибуцией [8. 239-241].

Видно, что парадигматические отношения согласных фонем являются сложными и разнообразными, следует подчеркнуть, что глубокие изучения особенностей фоне мы с точки зрения синтагматической будет способствовать выявлению большого количество вариантов.
В мировой лингвистики имеется, играет большое количество трактовые инвариантной и вариантной теории фонем, применение которых может привести к новым научным заключениям по узбекской и тюркской диалектологии.

Учёный языковед Д. Набиева, касаясь вопроса об инвариантности и вариантности в узбекском языке отмечает, что частности, объединенные общим признаком и различающиеся частными признаками, образуют инварианты вариантов, а варианты являются единицами, объединенными общими признаками и образующими определенную группу. По мнению учёного, отношение инвариант-вариант. Характерно для единиц всех пластов языка, а варианты считают с воздействующими на фонемы чувств единицами, путем сравнения вариантов выявляется субстанция, на основе которой определяются инварианты [6.14-37].

Действительно, фонема является инвариантной единицей и в процессе речи употребляется в нескольких вариантах. Следовательно, варианты фонем является самыми мелкими сегментными единицами.

Согласно теории пражской лингвистической школы, варианта делятся на позиционные, комбинаторные и стилистические.

Обязательные варианты делятся: позиционные, комбинаторные и стилистические.

Позиционные варианты - это форма фонемы по отношению к ударению, характеру слова, мелодии речи;

Комбинаторные варианты - это форма, образовавшейся под влиянием находящиеся рядам фонем;

Стилистические варианты связки стилем произношения.

Варианты, появившиеся в результате диалектных различий, чередующиеся в одной позиции без изменения смысла слова, называются факультативными вариантами. Кроме вышеуказанных вариантов имеются индивидуальные варианты, обусловленные речевыми особенностями говорящего.

Исследование особенности звуковой системы диалектов тюркских, в частности узбекского языка проводится с опорой на теоретические положения мировых фонологических школ.

Известно, что проблемы фонологического пласта на материале тюркских языков освещены А.М. Щербаком, который на материале древних письменных источников выделяет фонологических признаки и на основе существенных признаков восстановил систему согласных фонем тюркского праязыка [16. 97].

Известный тюрколог А.А. Баскаков путем сравнения четырёх моделей фонетической структуры одно - сложных слов определяет 


\begin{tabular}{|c|c|c|c|c|c|c|}
\hline \multirow{4}{*}{ Impact Factor: } & ISRA (India) & $=3.117$ & SIS (USA) & $=0.912$ & ICV (Poland) & $=6.630$ \\
\hline & ISI (Dubai, UAI & $=0.829$ & РИНЦ (Russia & $=0.156$ & PIF (India) & $=1.940$ \\
\hline & GIF (Australia) & $=0.564$ & ESJI (KZ) & $=8.716$ & IBI (India) & $=4.260$ \\
\hline & JIF & $=1.500$ & SJIF (Morocco & $=5.667$ & OAJI (USA) & $=0.350$ \\
\hline
\end{tabular}

фонетическое строение подобных слов тюркского праязыках.

Фонетико-фонологическая

система диалектов тюркских языков, в частности узбекского языка на основе принципов фонологической теории представлена в трудах таких языковедов, как А. Фитрат, Ш. Рахматуллаев, И. Кучкартаев, В.В. Решетов, Ф. Абдуллаев. В трудах этих ученых представлена информация о фонеме, и её вариантах в диалектах тюркского и узбекского языков. Наблюдается стремление к освещению соотношения языка и речи в фонетическом пласте, отличается, что проблема фонемы и её вариантов возникла на основе трактовок Л.В. Щербы и А.А. Реформатского. [10. 272-273].

Согласно концепции Московской фонологической школы в зависимости от степени разграничения формы слов с звуковой стороны выделяются две позиции фонем сильная позиция (позиция максимального разграничения) и слабая позиция (позиция минимального разграничения).

Позиция, мало подвергающая с я влиянию окружающих звуков, дифференциальная с перцептивной стороны, считается сильной позицией.

Варианты сильной позиции делятся на две группы: 1) основные позиционные варианты (аллофоны); 2) слабые комбинаторные позиции (аллофоны).

В классификациях позиции фонем отличается, что позиция, сильная по одному признаку может быть слабой для этой фонемы по другому признаку [10. 240-241].

В учение Московской фонологической школы фонемы рассматриваются, как составная часть слов морфем и при их разграничении понятие позиция считается важным признакам.

A.A. Реформатский разделяет слабый позиции на перцептивные слабые (со стороны познание) и сигнификативно слабые (со стороны различения) и отмечает, что первые означает образование вариаций фонем, а второе ее вариантов [13.74-95].

Для согласных фонем узбекского языка интервокальное положение и позиция конце слова являются слабой позицией, что в этой позиции они склонны к изменениям.

Фонемы могут иметь коррелятивные и не коррелятивные основные признаки. Общие для двух фонем признаки, имеющиеся в одной, и отсутствующие в другой считаются коррелятивными признаками [8. 19].

В отличие от литературного языка, в составе согласных диалектов этот процесс происходит подругому. Именно эти фонологические признаки выражают своеобразие диалектов.

Первоначальные сведения об оппозиции и корреляции фонем представлены в трудах видающихся мыслителей Востока Мусо алХорезми, Абу Али ибн Сино, М. Кашгари, А. Наваи, в «Бабурнаме» 3.М. Бабура [8. 19; 5. 39].

В кыпчакских говорах Намангана согласные по признаку звонкость/ глухость также являются коррелятивными парами: $\boldsymbol{\sigma}-\boldsymbol{n}$ [боно] якинда (недавно) // [пэно] пона (клин), $\boldsymbol{c}$-3 [сәмэн] (солома) // [зэмюн] замон (время) и др.

Согласных кыпчакских диалектов Намангана свои коррелятивные признаки в основном сохраняют в начале слова и имеют сильную позицию. Например: [бов] - боғ (пук), [бовлық]боғлиқ (связано), [полопэн] полопон (маленькая nтица), сильную позицию имеют начальные $\boldsymbol{\sigma}$ и $\boldsymbol{n}$, а в словах [кәвоп]- кабоб (кабаб-цашльк), [cәвоп] - савоб (благородная дело), [кътопым//кьтовим] - китобим (моя книга), [сәвъ] - сопи (рукоять) б и $n$ в интервокальном положении находятся в слабой позиции.

Фонемы $\boldsymbol{x}, \check{\boldsymbol{u}}, \boldsymbol{\mu}, \boldsymbol{\mu}, \boldsymbol{л}, \boldsymbol{p}$ в литературном языке по признаку звонкость/глухость не обладают коррелятивными отношениями и образуют пары по этому признаку. Как и в других диалектах, в диалектах кыпчакского диалекта Намангана разные факультативные варианты фонем образуют корреляцию (пару), и не меняя значение,

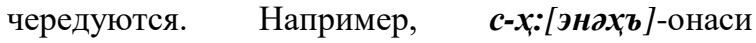

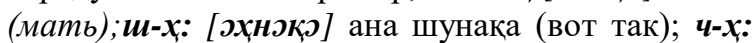
[хуовдыш] чойжўш (кумган)и др. Согласная фонема х старотюркском языке существовала как протеза, в рунических памятниках не встречается вообще, в некоторых современных тюркских языках имеет прочное место, в диалектах имеется протетический, в частности в азербайджанском языке и его диалектах: [хәрэx]-ўрок(коса), [хиввос] - новвос (бык); имеется также в узбекском литературном языке [xррыn] чарчамоқ (уставать), [xурnой] - хурпаймоқ (непорядичины), в туркменском: $[\boldsymbol{x} \boldsymbol{Y} \boldsymbol{\mu}]$-кун (день) и т.д.

Как результат следующей ступени развития праязыка звуки $\boldsymbol{c}, \boldsymbol{u}, \boldsymbol{u}, \quad 3$ в современном башкирском и якутском языках используются вместох. В частности, в якутском языке в интервокальном положении $\boldsymbol{x}$ считается звонким. В башкирском языке, $\boldsymbol{c}$-x: [xоз]-сўз (слово), [хурьв] - сариқ (жёлтый), [хқъз]- сиз (вы), [хуоң]- сўнг (после), [бөхуо-бўлса, (быть),[хюв]-соғ; в

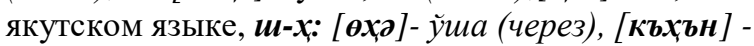
қиш (зима); ч-x̧: [nъx̧ax]-пичоқ (нож) [16.81].

В кыпчакских диалектах Намангана наблюдается, независимо от того, что тюркское или заимствованные это слово, чередование согласных $\boldsymbol{u}, \boldsymbol{u}, \boldsymbol{c}, \boldsymbol{x}$ : [энәхқъ], [эхнэқэ]. Это явление могут быть рассмотри как один из появлений средств праязыка в диалектах. В кипчакских диалекта Намангана встеречаются комбинаторные варианты фонем р-л: [дувэл] - 


\begin{tabular}{|c|c|c|c|c|c|c|}
\hline \multirow{4}{*}{ Impact Factor: } & ISRA (India) & $=3.117$ & SIS (USA) & $=0.912$ & ICV (Poland) & $=6.630$ \\
\hline & ISI (Dubai, UAE & $=0.829$ & РИНЦ (Russia & $=0.156$ & PIF (India) & $=1.940$ \\
\hline & GIF (Australia) & $=0.564$ & ESJI (KZ) & $=8.716$ & IBI (India) & $=4.260$ \\
\hline & JIF & $=1.500$ & SJIF (Morocce & $=5.667$ & OAJI (USA) & $=0.350$ \\
\hline
\end{tabular}

девор (стена), г-й: [mүйын] тугун(тюк). под влиянием окружающих фонем.

В слабой позиции могут выпадать различительные признаки коррелятивных пар. Этот фонологический процесс получил название нейтрализации [6.14-37].

Как отличает известный ученый тюрколог A.M. Щербак, фонетико-фонологические особенности тюркского праязыка постепенно, сами по себе адаптируются к современным условиям. В тюркском праязыке и в некоторых тюркских языках звонкие и глухие согласные могут иметь сильную позицию, однако это явление не представляется важным с точки зрения фонологической. [16.88-89]. Сравним:

\begin{tabular}{|c|c|c|c|c|c|c|}
\hline азарб. & тюркск. & тюркм. & мувинск. & татарск. & узбекск. & $\begin{array}{c}\text { диал. } \\
\text { Намангана }\end{array}$ \\
\hline дабан & тебән & дәбан & даван & табән & тавэн & товон \\
\hline дәйъб & тайъб & тәйъб & дайъв & тәйъn & тәйиб & mъйzวныли \\
\hline дүрнә & түрнд & дүрнэ & дүрйәйә & дөрнә & турна & түрна \\
\hline төрпак & топрәк & төпрәк & дубурак & түфррәк & тупроқ & турпюк \\
\hline табақ & maбаг & мәбаз & тавак & табәк & товоқ & мәво://тәвэқ \\
\hline mук & $m y \check{u}$ & $m y \check{u}$ & $\partial \gamma \kappa$ & тўк & тук & $m \gamma \kappa$ \\
\hline
\end{tabular}

В научных исследованиях по тюркологии отличается, что имеется масштаб тюркских языков, сохранивших согласно эволюционному развитию звуков и фонем особенности праязыка, в частности подчёркивается что в чувашском, хакасском, шоорском языках на отношению смывчно-взрывной фонеме $\boldsymbol{\sigma}$ её глухая пара [n] в оппозиции имеет сильную позицию [16.93]. Например:

\begin{tabular}{|c|c|c|c|c|}
\hline Хакасск. & Тюркск. & Казахск. & Узбекск. & диал. Намангана \\
\hline$n a k$ & бaz & $б a в$ & бэғ & 658 \\
\hline naķa & бақ̧а & баке & бақа & бэқо \\
\hline палих & бәлък & бальк & балық & больқ \\
\hline палта & балта & балте & болтә & болто \\
\hline nap & вap & бар & бор & бэр \\
\hline noc & бали & бac & бош & бош \\
\hline
\end{tabular}

В других тюркских языках в анлауте также в литературных словах может быть использовано фонема [n]. Например:

\begin{tabular}{|c|c|c|c|c|}
\hline тюркск. & тюркменск. & уйхурск. & узбекск. & диал. Намангана \\
\hline nyc & $n_{Y c}$ & $n b c$ & пис (яииринмок) & $n b c$ \\
\hline- & - & пәлчък & балчиқ & болчьық//пэлчыққ \\
\hline- & палта & - & болта & бэлто \\
\hline- & - & пака & бақ̧а & бวқ̧ว \\
\hline nym & $n_{Y m}$ & nym & ö̈ķ & nYm//১ŭэқ \\
\hline- & - & nam & бот & бот \\
\hline бичен & бичән & пичан & пичан & бъчән \\
\hline
\end{tabular}

Наличие $\boldsymbol{\sigma}>\boldsymbol{n}, \boldsymbol{\sigma}>\boldsymbol{\boldsymbol { c }}, \boldsymbol{\sigma}>\boldsymbol{\boldsymbol { M }}$ свидетельствует о наличии неразрывной связи тюркского праязыка и современных тюркского языков.

Как было отличено выше, по мнению А.М. Щербака, в праязыке сильные и слабые звонких и глухих не имели фонологический значимости. Использование глухих на месте звонких и или шумных на место сонорных образует репрезентацию, т.е. чередование. Он также отмечает, что согласная фонема $\boldsymbol{м}$ этимологически появилась в результате корреляции $\boldsymbol{n}$ по звучности и шума и объясняет следующим образом: П(б) $\rightarrow \boldsymbol{\beta} / \boldsymbol{M}$ [16. 97].

По мнению некоторых исследователей сонорные звуки $\boldsymbol{m ,}, \boldsymbol{p}, \boldsymbol{л}$, н не употреблялись в начале слова. Начальный звук $\boldsymbol{M}$ как результат озвончения $[\boldsymbol{n}]$, т.е. переход его в [б], а [б]соответственно перешел в [м]. Узбекский ученый-языковед Х.Неъматов показывает развитие губных согласных следующим образом: $\boldsymbol{\Pi}>(\boldsymbol{\phi}) \rightarrow \boldsymbol{b}>\boldsymbol{b}, \boldsymbol{b}(\boldsymbol{w}) \rightarrow \boldsymbol{M}$ [7.61-66] 


\begin{tabular}{|c|c|c|c|c|c|c|}
\hline \multirow{4}{*}{ Impact Factor: } & ISRA (India) & $=3.117$ & SIS (USA) & $=0.912$ & ICV (Poland) & $=6.630$ \\
\hline & ISI (Dubai, UAE & $=0.829$ & РИНЦ (Russia & $=0.156$ & PIF (India) & $=1.940$ \\
\hline & GIF (Australia) & $=0.564$ & ESJI (KZ) & $=8.716$ & IBI (India) & $=4.260$ \\
\hline & JIF & $=1.500$ & SJIF (Morocce & $=5.667$ & OAJI (USA) & $=0.350$ \\
\hline
\end{tabular}

Как и в некоторых тюркских языках в кипчакских диалектах Намангана сильная фонема литературного языка [б] произносится как $\boldsymbol{\boldsymbol { m }}$ [мурын]- бурун (нос), [муййын]-буйин (щея), [мъннәрсә] бир нарса (кое-что). Хотя и большинстве тюркских языков начальные $\boldsymbol{\sigma} / \boldsymbol{n}$ употребляются как в оригинале, в некоторых перешли в коррелятивное $\boldsymbol{м}$. Сравним:

\begin{tabular}{|c|c|c|c|c|c|c|}
\hline тюрским. & азерб. & киргизск. & уйзурск. & хакасск. & узбекск. & $\begin{array}{l}\text { диал. } \\
\text { Намангана }\end{array}$ \\
\hline 663 & 663 & $M b 3$ & - & миз & бигиз & $6 Y^{2} y^{3}$ \\
\hline батир & батир & батыр & бamyp & матир & ботир & ботылыр \\
\hline балта & балта & балта & палта & малта & болта & болто \\
\hline балчих & балчих & - & - & малчах & балчиқ & болчыцқ \\
\hline буйук & буйук & - & - & мүзек & буйук & ульық \\
\hline борсук & борсук & - & - & морсук & бўрсиқ & бөрсыцқ \\
\hline бен & бен & мен & мЭн & мин & мен & мЭн \\
\hline дана & дана & музоо & мозай & - & бузоқ & бүзәв \\
\hline
\end{tabular}

Анализ примеров показывает, что в большинстве тюркских языков сохраняются фонетико-фонологические особенности согласных звуков, относящихся к среднему периоду развития праязыка. В частности, и в кипчакских диалектах Намангана встречаются некоторые морфологические показатели древнего языка: $\boldsymbol{n / б - ~ [ у н а қ а ~ + ~ б а с ] ~ у н а қ а ~ + ~ ( э ) м а с ~ ( н е т а к ) , ~}$ $[$ кэчә + бас] кеча + (э)мас; (не вчера); $\boldsymbol{c} / 3 / \boldsymbol{p}$ [бэр+ac+mъм] - бор+ар+дим (шёл), [кэл+ac+mъм ] -кел+ар+дим (пришёл бы).

\section{Conclusion}

В заключении можно отметить, что синтагматические отношения системы согласных кипчакского диалекта Намангана обладают специфическими особенностями. Изучение позиционно-комбинаторных вариантов согласных звуков диалектиков узбекского языка с точки зрения инвариантной и вариантной концепции дает возможность для выработки особенных научных выводов о тюркских языках и своеобразиях их фонетико-фонологической структуры.

\section{References:}

1. Abduazizov, A. (1992). Uzbek tili fonologiyasi va morfonologiyasi. Toshkent.

2. Abduazizov, A. (n.d.). Inostrannye yazyki $v$ shkole. Tashkent, №6, pp.101-105.

3. Baskakov, N. A. (1969). Vvedenie v izuchenie tyurkskikh yazykov. Moscow.

4. Vasil'ev, V. A. (1970). Fonetika angliyskogo yazyka (teortichesk. kurs na angl. yazyke). Moscow.

5. Zhamolkhonov, X. (2008). Xozirgi uzbek adabiy tili. 1-kitob. Toshkent.

6. Nabieva, D. A. (2005). Uzbek tilining turli satxlarida umumiylik-khususiy-lik dialektikasining namoen by̆lishi. Toshkent.

7. Ne"matov, X. (1992). Uzbek tili tarikhiy fonetikasi. Toshkent: Ukituvchi.

8. Nurmonov, A. (1990). Uzbek tili fonolo-giyasi va morfonologiyasi. Toshkent.
9. Nurmonov, A. (2012). Tanlangan asarlar. 1zhild. Toshkent: Akademnashr.

10. Nurmonov, A. (2012). Tanlangan asarlar. 2zhild. Toshkent: Akademnashr.

11. Reformatskiy, A. A. (1970). Iz istorii otechestvennoy fonologii. Moscow: Nauka.

12. Reformatskiy, A. A. (1967). Vvedenie $v$ yazykovedenie. Moscow.

13. Reformatskiy, A. A. (1975). Fonologicheskie etyudy. Moscow: Nauka.

14. Trubetskoy, N. S. (2000). Osnovy fonologii. Per. s nem. A.A.Kholodovicha; Podred. S.D.Kantsiel'sona (Eds.). Seriya "Klassichiskiy uchebnik". (p.352). Moscow: Aspekt Press.

15. Shcherba, L. V. (1963). Fonetika frantsuzskogo yazyka. Moscow.

16. Shcherbak, A. M. (1970). Sravnitel'naya fonetika tyurkskikh yazykov. Leningrad. 